\title{
A Rare Case of a Ruptured Ovarian Pregnancy
}

\author{
Dr. N.V. Manjula, M.B.B.S., M.S., ${ }^{1}$ Dr. Gaurav Sundar, M.B.B.S., ${ }^{1}$ Dr. Shakila \\ Shetty, M.B.B.S.m D.G.O., M.S., ${ }^{1}$ Dr. B. K. Sujani, M.B.B.S., M.S., ${ }^{1}$ Dr. \\ Mamatha, M.B.B.S., M.S. ${ }^{1}$
}

Key Words: Ovary; Pregnancy; Pregnancy, Ectopic; Rupture, Spontaneous

\begin{abstract}
Ovarian pregnancy is a rare type of extrauterine pregnancy accounting for 1 to $3 \%$ of all extrauterine pregnancies. We report a rare case of a ruptured ovarian pregnancy. A 22 year old, gravida 2 para 1 living 1 was admitted with amenorrhea of 4 weeks and 6 days with chief complaints of severe acute lower abdomen pain. Urine beta hCG pregnancy test was positive. Ultrasonogram of pelvis revealed left sided ruptured adnexal mass with moderated hemoperitoneum. Laparotomy was performed and a diagnosis of ruptured ovarian pregnancy was made. The mass was excised and sent for histopathological examination which confirmed the diagnosis. Although ovarian pregnancy is rare, in any case of a ruptured ectopic pregnancy where the tubes are found to be normal on laparotomy, an ovarian pregnancy must be ruled out. Early detection and prompt diagnosis can preserve the future fertility of the woman.
\end{abstract}

${ }^{1}$ Department of Obstetrics and Gynecology, M.S. Ramaiah Medical College, Bangalore,

\section{Introduction}

Ovarian pregnancy is a rare type of extrauterine pregnancy. Its incidence is about 1 in 7,000 to 1 in 60,000 pregnancies and accounts for about 1 to $3 \%$ of all extrauterine pregnancies. In primary ovarian pregnancy the ovum is fertilized in the peritoneal cavity and then implants onto the ovary. In the secondary type, there is a tubal abortion or perforation of the tube with secondary implantation of the embryo on the ovarian surface. Here, we report a rare case of a ruptured ovarian pregnancy

\section{Case report}

A 22 year old, gravida 2 para 1 living 1 , came to our hospital with amenorrhea of 4 weeks and 6 days with complaints of sudden onset pain in the lower abdomen. No associated vaginal bleeding was observed. Her previous cycles were regular with 3-4 days of bleeding every 30 days,

Please cite this paper as: Manjula NV, Sundar G, Shetty S, Sujani BK, Mamatha. A Rare Case of a Ruptured Ovarian Pregnancy. Proc Obstet Gynecol. 2010 Oct;1(2): Article 4 [ 5 p.]. Available from:

http://ir.uiowa.edu/pog/vol1/iss2/5/. Free full text article.

Corresponding author: Dr. Gaurav Sundar, No. 11, $1^{\text {st }}$ Cross, Judicial Layout, R.M.V. $2^{\text {nd }}$ Stage, Sanjay Nagar, Bangalore - 560094, Karnataka, India. gauravsundar@gmail.com

This is an Open Access article distributed under the terms of the Creative Commons Attribution 3.0 Unported License (http://creativecommons.org/licenses/by/3.0), which permits unrestricted use, distribution, and reproduction in any medium, provided the original work is properly cited. 
average flow and no dysmenorrhea. Her first pregnancy was a spontaneous conception and she had a full term normal vaginal delivery in a hospital. There were no post partum complications and no history of contraceptive use.

Her general examination was normal except for mild pallor. On abdominal examination, there was mild tenderness in the left iliac fossa. Per speculum examination, the vagina and cervix were normal. Per vaginal examination revealed normal uterine size and no cervical motion tenderness, but a palpable tender mass was felt in the left fornix. Urine beta hCG pregnancy test was positive. On ultrasonography, no gestational sac was seen in utero but a left sided ruptured adnexal mass was seen. A moderate hemoperitoneum was present with fluid in the cul de sac. Emergency laparotomy was performed with a preoperative provisional diagnosis of left ruptured tubal pregnancy. Intraoperatively, the uterus was normal in size and both the tubes were found to be normal. The size of both ovaries was normal. A left ovarian hemorrhagic mass measuring $1 \times 1 \mathrm{~cm}$ was seen with an actively bleeding vessel at the posterior surface of the ovary. The left fallopian tube was found completely normal and separate from the ovary. The hemorrhagic ovarian mass was completely excised and was sent for histopathological examination with a provisional differential diagnosis of either ruptured ovarian pregnancy or hemorrhagic corpus luteum cyst. Meticulous coagulation of the bleeding sites was done to establish and maintain hemostasis. The majority of the normal ovarian tissue was left in situ. Her postoperative recovery was uneventful. Urine pregnancy test done on the $3^{\text {rd }}$ post operative day was negative. Histopathology of the excised ovarian mass showed hemorrhage, fibrin, chorionic villi and trophoblasts with dense neutrophilic infiltrate indicating infected ovarian implantation (Figure 1). However, she had no clinical evidence of infection. She was discharged on the fifth post-operative day.

\section{Discussion}

Early diagnosis of an ovarian pregnancy is perhaps the most difficult compared to all the other types of extra uterine gestations. The signs and symptoms of ruptured ovarian pregnancy are similar to those of disturbed tubal pregnancy. Although an adnexal mass is palpable in many cases of ovarian pregnancy, the mass is frequently confused for a hemorrhagic corpus luteum cyst or ruptured tubal pregnancy. ${ }^{1}$ With a few exceptions, the initial diagnosis is made on the operating table and the final diagnosis only on histopathology on the basis of the four Spiegelberg criteria ${ }^{2}$ :

- The gestational sac is located in the region of the ovary.

- The ectopic pregnancy is attached to the uterus by the ovarian ligament. 
- Ovarian tissue in the wall of the gestational sac is proved histologically.

- The tube on the involved side is intact.

In the present case, we suspected a ruptured tubal pregnancy preoperatively on the basis of positive urine beta hCG pregnancy test and ultrasonography findings.
The intraoperative finding of normal tubes bilaterally was surprising, and to confirm the diagnosis, tissue samples from the excised left hemorrhagic ovarian mass were sent for histopathological examination. The presence of trophoblastic activity in the ovarian tissue confirmed an ovarian pregnancy in accordance to the four Spiegelberg criteria.

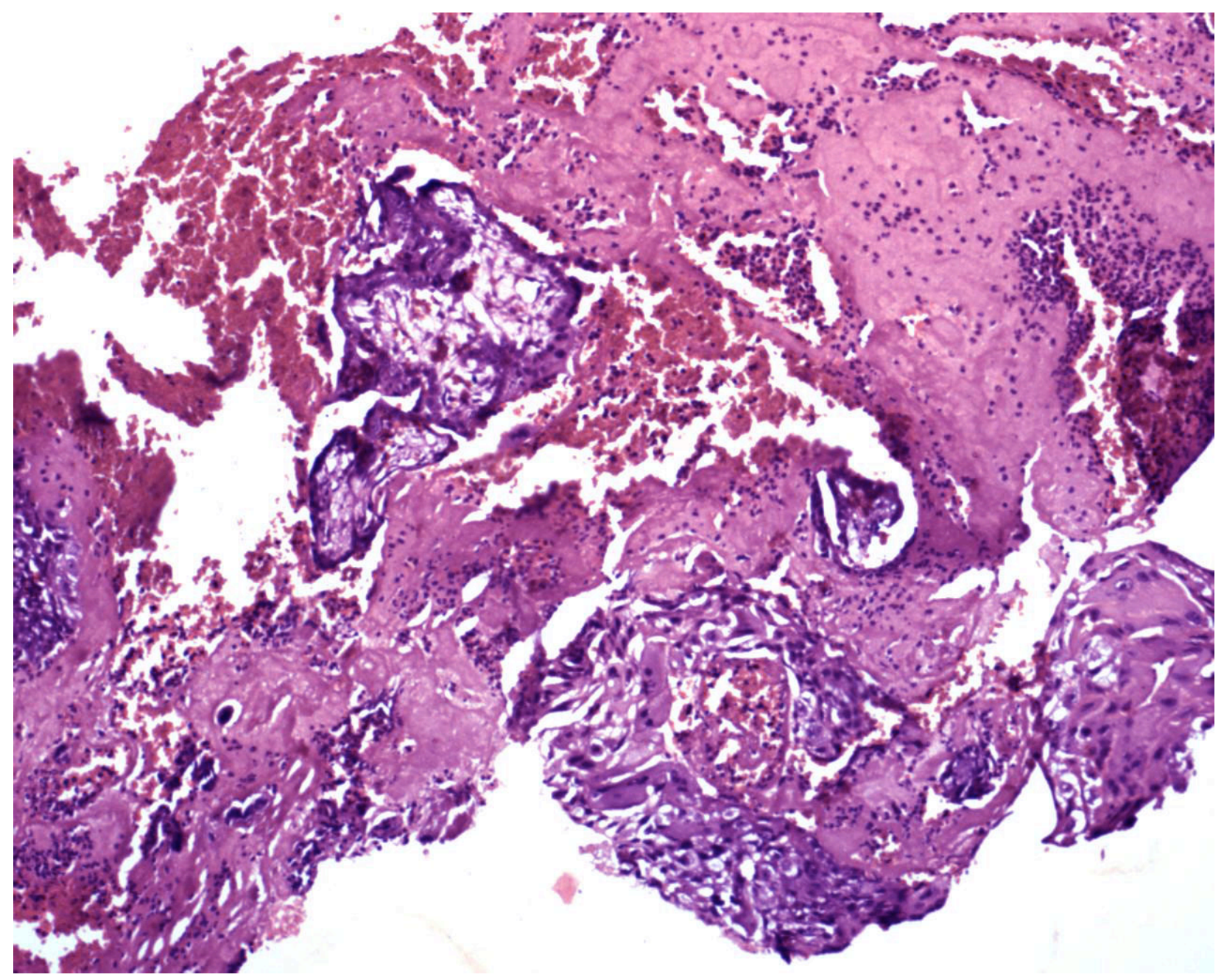

Figure 1 - Histopathology of ovarian tissue, showing chorionic villi and trophoblasts with dense neutrophilic infiltrate

Our case has a few points of interest. Firstly, when a patient is suspected of having a ruptured tubal pregnancy and is taken up for laparotomy, if the tubes are found to be normal, a thorough search should be made for a ruptured ovarian pregnancy. This is especially true in a case with a hemoperitoneum. 
Secondly, the classic management of ruptured ovarian pregnancy is surgical, like any other ruptured ectopic pregnancy. The extent of surgery varies according to the amount of tissue destruction that has occurred. Patients with an ovarian pregnancy have a good prognosis for future fertility and therefore conservative surgical management, as in our case, is advocated. Radical procedures like oophorectomy have long been considered inappropriate if the diagnosis has been made early enough to preserve the ovary. The outcome recorded in a study by $M D$ Helde et al had recorded that wedge or partial resection and repair is adequate to control bleeding from early ovarian pregnancies. ${ }^{3}$

Thirdly, the use of methotrexate in a carefully selected case may further be beneficial in conserving future fertility. However, the presence of free peritoneal fluid, presumably blood, as in our case, is considered by many to be a contraindication to methotrexate therapy, because it may indicate ongoing tubal rupture. ${ }^{4}$, ${ }^{5}$ Moreover, the difficulty in diagnosis without laparotomy or laparoscopy is an important limiting factor. The authors agree with Seinera et $\mathrm{al}^{6}$ concluding that as laparoscopy is required for diagnosis, it is logical to effect definitive surgical management at the same time.

Fourthly, the cause of primary ovarian pregnancy is still unclear. Literature shows that the risk of ovarian pregnancy is found to be higher in those who use intrauterine contraceptive devices. ${ }^{7}$ Cases of ovarian pregnancy have also been reported following ICSI-ET ${ }^{8}$ and vaginal douching. ${ }^{9}$ Unlike tubal pregnancy where there is a $15 \%$ chance of recurrence, no case of a repeat ovarian pregnancy has been reported ${ }^{10}$ which indicates that a previous ovarian pregnancy may not be a risk factor for its recurrence. In our case, none of the above mentioned risk factors were present.

\section{Conclusion}

Diagnosing an ovarian pregnancy is difficult. Primary ovarian pregnancy may occur without the presence of any of the classical risk factors for ectopic pregnancy. When the clinician is suspecting a ruptured tubal pregnancy, intraoperative finding of normal tubes should alert the surgeon keep an ovarian pregnancy in mind. Early diagnosis and prompt treatment can allow for conservative surgery and preserve the future fertility of the patient.

\section{References}

1. Nwanodi $\mathrm{O}$, Khulpateea $\mathrm{N}$. The preoperative diagnosis of primary ovarian pregnancy. J Natl Med Assoc. 2006 May;98(5):796-8.

2. Speert H. Otto Spiegelberg. Criteria of Ovarian Pregnancy. In: Obstetric and Gynecologic Milestones, the MacMillan Company, New York, 1958. p. $255 \mathrm{ff}$

3. Helde MD, Campbell JS, Himaya A, Nuyens AJ, Cowley FC, Hurteau GD. Detection of unsuspected ovarian pregnancy by wedge resection. Can Med Assoc J. 1972 Feb 5;106(3):237-42.

4. Glock JL, Johnson JV, Brumsted JR. Efficacy and safety of single- 
dose systemic methotrexate in the treatment of ectopic pregnancy. Fertil Steril. 1994 Oct;62(4):716-21.

5. Shalev E, Peleg D, Bustan M, Romano S, Tsabari A. Limited role for intratubal methotrexate treatment of ectopic pregnancy. Fertil Steril. 1995 Jan;63(1):20-4.

6. Seinera P, Di Gregorio A, Arisio R, Decko A, Crana F. Ovarian pregnancy and operative laparoscopy: report of eight cases. Hum Reprod. 1997 Mar;12(3):60810.

7. Yüce $K$, Baykal $C$, Yüksel $H$, Apikoğlu M, Akkaya A. Ovarian pregnancy with intrauterine device in situ. Arch Gynecol Obstet. 2005 Feb;271(2):168-71.

8. Dursun $P$, Gultekin M, Zeyneloglu HB. Ovarian ectopic pregnancy after ICSI-ET: a case report and literature review. Arch Gynecol Obstet. 2008 Aug;278(2):191-3.

9. Alataş E, Yildirim B, Oztekin O, Gezgin T. Laparoscopic management of a primary ectopic ovarian pregnancy and vaginal douching as a possible cause. Arch Gynecol Obstet. 2008 Apr;277(4):363-5.

10. Sergent $F$, Mauger-Tinlot $F$, Gravier A, Verspyck E, Marpeau L. [Ovarian pregnancies: revaluation of diagnostic criteria]. J Gynecol Obstet Biol Reprod(Paris). 2002 Dec;31(8):741-6. 